\title{
Bacterial composition and spatiotemporal variation in sediments of Jiaozhou Bay, China
}

\author{
Xin Liu • Hang-Wei Hu • Yu-Rong Liu • Ke-Qing Xiao • \\ Fan-Sheng Cheng $\cdot \mathbf{J i} \mathrm{Li} \cdot \mathrm{Tian}$ Xiao
}

Received: 14 March 2014 / Accepted: 26 November 2014 / Published online: 10 December 2014

(C) Springer-Verlag Berlin Heidelberg 2014

\begin{abstract}
Purpose Although coastal marine sediments harbor diverse bacteria with important ecological and environmental functions, a comprehensive view of their community characteristics is still lacking in typical environments along the China coast. We studied the diversity and composition of bacterial community in the sediment of Jiaozhou Bay and characterized their spatiotemporal patterns, aiming to analyze the effects of geographic heterogeneity, seasonal difference, anthropogenic activity, and eutrophication gradient on the bacterial ecology. Materials and methods Sixteen full-length bacterial 16S rRNA gene clone libraries were constructed from the sediment bacteria at four stations (A5, B2, D1, and D7) of Jiaozhou Bay over four seasons (February, May, August, and November). The bacterial diversity and community structure variation were analyzed.

Results and discussion A total of 1088 16S rRNA gene sequences and 746 distinct operational taxonomic units (OTUs) (at $97 \%$ sequence similarity level) were retrieved from the 16 clone libraries. Libraries of each sample revealed a high diversity, and a total of 17 bacterial phyla were identified.
\end{abstract}

Responsible editor: John R. Lawrence

Electronic supplementary material The online version of this article (doi:10.1007/s11368-014-1045-7) contains supplementary material, which is available to authorized users.

X. Liu • H.-W. Hu • Y.-R. Liu • K.-Q. Xiao · J. Li

State Key Laboratory of Urban and Regional Ecology, Research

Center for Eco-environmental Science, Chinese Academy of

Sciences, Beijing 100085, China

F.-S. Cheng · T. Xiao ( $₫)$

Key Laboratory of Marine Ecology \& Environmental Sciences,

Institute of Oceanology, Chinese Academy of Sciences,

Qingdao 266071, China

e-mail: czliuieie@sina.com
Bacteria lineages Proteobacteria (mostly $\gamma$-Proteobacteria and $\delta$-Proteobacteria), Actinobacteria, Bacteroidetes, and Planctomycetes, which are commonly found in marine sediments, were the dominant divisions in our samples. Meanwhile, some uncommon phyla, such as Deinococcus-Thermus and Lentisphaerae, were also detected. Distinct spatial patterns and noticeable seasonal variations of bacteria community were observed, indicating that environmental heterogeneity in spatial variation other than in temporal variation may be more important in determining the bacterial communities. Most of the abundant OTUs were related to sequences retrieved from the heavy-metal-polluted environments, indicating that the Jiaozhou Bay might be influenced by pollution. Conclusions The bacterial communities in Jiaozhou Bay sediments are highly diverse. The four typical stations that we chose might experience different anthropogenic effects and eutrophication gradients, which shaped their bacterial community composition. The environment of Jiaozhou Bay may be under pressure exerted by multi-dimension anthropogenic activities. This study provided a novel insight into the bacterial community variations in Jiaozhou Bay, enriching knowledge about ecological bioindicators and mechanisms that maintain bacterial diversity and shape bacterial community composition.

Keywords 16S rRNA clone library · Diversity · Jiaozhou Bay $\cdot$ Sediment bacteria $\cdot$ Spatiotemporal distribution

\section{Introduction}

Surface sediment bacteria play a significant ecological and biogeochemical role in marine ecosystems due to their high abundance relative to the overlying water column and their key role in organic matter decomposition and nutrient cycling (Wang et al. 2012). As one of the most variable marine 
habitats, coastal sediments are generally characterized by a high biodiversity and complicated community structure and distribution in response to environmental heterogeneity, seasonal variation, and anthropogenic effects (Danovaro and Pusceddu 2007; Aguiló-Ferretjans et al. 2008). Moreover, it was demonstrated that bacterial communities have great potential to be used as sensitive indicators of variation and contamination in coastal aquatic sediments (Lachmund et al. 2003; Sun et al. 2012). Although large populations of bacteria are well documented in coastal surface sediments, their biogeographical patterns under anthropogenic disturbances and environmental gradients, as well as temporal variations remain largely unexplored (Bissett et al. 2006; Bertics and Ziebis 2009), especially in heterogeneous marine ecosystems such as Jiaozhou Bay (JZB).

Jiaozhou Bay is a large semi-enclosed water body of the temperate Yellow Sea in China. It covers an area of about $390 \mathrm{~km}^{2}$ with an average depth of about $7 \mathrm{~m}$, connecting to the outside seawater via a narrow opening about $2.5 \mathrm{~km}$ in width (Dai et al. 2007). The environmental quality of Jiaozhou Bay has deteriorated dramatically in the past three decades due to rapid development in agriculture, industry, urbanization, and mariculture in the surrounding areas (Dang et al. 2008b; Gao and Chen 2012). Several small rivers form the major sources of discharged industrial and sewage wastewater bring excessive nutrients into the northeast of the bay (Shi et al. 2011). Meanwhile, sporadic oil spilling from the commercial ports near the bay mouth, intensive maricultural practices at the north area, along with red tides all make the situation even worse (Wang et al. 2008; Dang et al. 2010b; Deng et al. 2010). A wide spectrum of environmental conditions and accordingly a widely varying bacterial community structure have already drawn the JZB many research interests in recent years (Dang et al. 2008a, b, 2009b, 2010b). To date, however, studies that describe the spatiotemporal variations of the bacterial communities in JZB sediments are still limited. In this study, four stations were chosen with different sources of pollution and various levels of eutrophication, representing typical habitats of JZB to study the structure and dynamics of coastal bacterial communities.

This study used 16S rRNA clone library analysis to determine the diversity and spatiotemporal distribution of sediment bacteria in different JZB environmental conditions. Our primary focus was to find the bacterial biogeographical patterns in the four distinctive stations over different seasons, which is the study of "who is where and at what abundance and why," providing knowledge about ecological mechanisms that maintain diversity and shape sediment bacterial composition in JZB. In our previous research by denaturing gradient gel electrophoresis (DGGE), we investigated the sediment bacterial community composition in ten stations of JZB over four seasons (Liu et al. 2011). Here, we can also compare the bacteria community structures revealed by DGGE and by clone library analysis to provide useful information for future research.

\section{Materials and methods}

\subsection{Site description and sampling}

\subsubsection{Sampling sites}

Jiaozhou Bay is located in northern China $\left(35^{\circ} 43^{\prime}-36^{\circ} 18^{\prime} \mathrm{N}\right.$, $120^{\circ} 04^{\prime}-120^{\circ} 23^{\prime} \mathrm{E}$ ) and is the largest semi-enclosed water body along the southwest coast of the Yellow Sea. The bay is dominated by intertidal and shallow subtidal areas. JZB tides induce strong turbulent mixing, resulting in nearly homogeneous vertical profiles of seawater temperature and salinity. More than 10 small seasonal rivers enter JZB with varying water and sediment loads, including the Yanghe, Dagu, and Licun Rivers (Liu et al. 2005). Because of the increases in the population and commerce in the Qingdao city, the majority of these rivers have become canals for industrial and domestic waste discharge. In recent years, certain areas of JZB have been affected by continuously increasing anthropogenic activities such as land reclamation, port construction, landfill, and reservoir construction (Shi et al. 2011).

\subsubsection{Sample collection and physicochemical properties}

Sediment samples were collected from four stations (A5, B2, D1, and D7) of JZB (Fig. 1). Stations A5 and B2 are located in the inner bay (characterized by yellow-gray sandy mud), station D1 is located in the mouth of the bay (characterized by gray-black ooze), and station D7 is in the outer bay (characterized by yellow-gray muddy sand). The four stations can also be grouped by the pollution status. B2 is a less polluted station, A5 is a heavily polluted station, and D1 and D7 represent the seaport-influenced station and the station near the outside sea, respectively. Samples were collected in May (spring), August (summer), and November (fall) 2008 and in February (winter) 2009, using a stainless-steel $0.05 \mathrm{~m}^{2}$ Gray O'Hara box corer. Only undisturbed surface samples with clear overlying water were used to ensure the integrity of the surface sediment structures. Surface sediment samples $(5 \mathrm{~cm}$ depth) were taken aseptically with sterile 60 -ml syringes (luer end removed), homogenized, and stored in airtight sterile plastic bags at $-20{ }^{\circ} \mathrm{C}$ and stored at $-80{ }^{\circ} \mathrm{C}$ after transported to the laboratory. We obtained the following sediment physicochemical parameters from the Ecological Environment Monitoring Station in JZB: total nitrogen (TN), total phosphorus (TP), organic nitrogen $(\mathrm{ON})$, organic carbon $(\mathrm{OC})$, organic matter (OM), and moisture content (MC) (Table 1). In some cases, we were unable to obtain data due to engineering failure or substrate characteristics (station D1). Some basic 


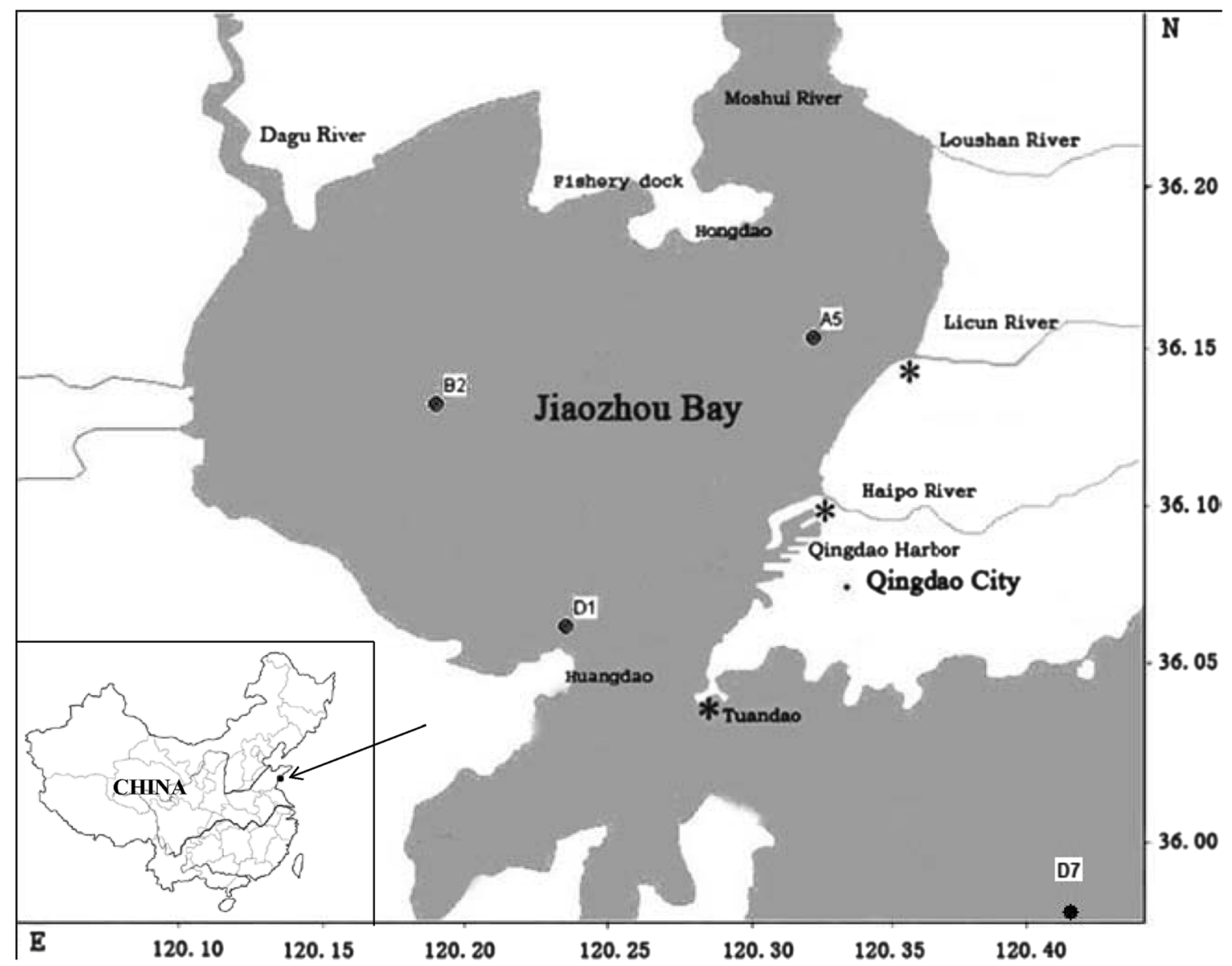

Fig. 1 Location of the Jiaozhou Bay and the four sampling stations

texture, such as the particle size, of the sediment samples was limited because the monitoring station in JZB only measured this parameter in February and August of each year.

\subsection{DNA extraction and PCR amplification}

DNA was extracted from sediment samples $(0.5 \mathrm{~g})$ in triplicate with the Power Soil DNA Isolation kit (MoBio, USA) according to the manufacturer's instruction, and the extracted DNA concentration was determined with Nanodrop ${ }^{\circledR}$ ND-1000 Spectrophotometer (NanoDrop Technologies). The presence of high molecular weight DNA (ca. 15,000 bp) in the extracts was verified by comparing the banding pattern of the sample with DNA molecular weight standard electrophoresed on $0.8 \%$ agarose gel. The DNA was stored at $-80{ }^{\circ} \mathrm{C}$ until amplification by polymerase chain reaction (PCR).

The bacterial 16S rRNA genes were amplified (Premix Ex Taq ${ }^{\mathrm{TM}}$, Takara) using the universal bacterial 16S rDNA gene primer set 27F (5'-AGAGTTTGATCACTGGCTCAG-3') and 1492R (5'-TACGGYTACCTTGTTACGAC-3' (Baker et al. 2003). Bovine serum albumin was added to reduce inhibition by humic substances. Amplification was performed with an initial denaturation step at $95^{\circ} \mathrm{C}$ for $5 \mathrm{~min}, 30$ cycles of $94{ }^{\circ} \mathrm{C}$ for $1 \mathrm{~min}, 56{ }^{\circ} \mathrm{C}$ for $1 \mathrm{~min}, 72^{\circ} \mathrm{C}$ for $2 \mathrm{~min}$, and a final extension at $72{ }^{\circ} \mathrm{C}$ for $10 \mathrm{~min}$. All PCR products were checked via $1 \%$ agarose gel electrophoresis.

\subsection{Construction of clone libraries}

The PCR products from the three experimental replicates were combined (to reduce stochastic PCR bias) and gel purified. The cleaned PCR products were cloned into Takara pMD-18T simple cloning vector (Takara, Japan), and the ligation products were transformed into competent Escherichia coli TOP10 cells. Recombinants were isolated on Luria-Bertani (LB) indicator plates supplemented with X-Gal-IPTG and $100 \mu \mathrm{g} \mathrm{ml}^{-1}$ ampicillin at $37{ }^{\circ} \mathrm{C}$ for $12-14 \mathrm{~h}$ (Dang et al. 2010a). Approximately 180 randomly selected white colonies per sample were cultured overnight in $1.5 \mathrm{ml}$ Luria Broth media at $37{ }^{\circ} \mathrm{C}$ placed on an orbital shaker at $250 \mathrm{rpm}$. Representative genotypes were determined via restriction fragment length polymorphism (RFLP). All positive colonies were checked with the M13 and RV-M primers. Amplimers of correct size were separately digested using $M s p \mathrm{I}$ (NEB) and HhaI (NEB). Restriction fragments were screened on $3 \%$ agarose gel, running at $100 \mathrm{~V}$ in $1 \times$ Tris-borate-EDTA (TBE) buffer for $50 \mathrm{~min}$. 
Table 1 Sediment physicochemical parameters at the sampling sites in the Jiaozhou Bay over different seasons

\begin{tabular}{|c|c|c|c|c|}
\hline Station & & A5 & $\mathrm{B} 2$ & D7 \\
\hline Longitude (E) & & $\mathrm{E} 120^{\circ} 19^{\prime} 48^{\prime \prime}$ & $\mathrm{E} 120^{\circ} 11^{\prime} 12^{\prime \prime}$ & E120 ${ }^{\circ} 25^{\prime} 30^{\prime \prime}$ \\
\hline Latitude $(\mathrm{N})$ & & $\mathrm{N} 36^{\circ} 09^{\prime} 18^{\prime \prime}$ & $\mathrm{N} 36^{\circ} 08^{\prime} 00^{\prime \prime}$ & $\mathrm{N} 35^{\circ} 59^{\prime} 00^{\prime \prime}$ \\
\hline \multirow[t]{7}{*}{ February } & Moisture content (MC) (\%) & 43.6 & 34.3 & 19.3 \\
\hline & Total phosphorus (TP) (mg/kg) & 554.7 & 361.9 & 377.6 \\
\hline & Total nitrogen $(\mathrm{TN})(\mathrm{mg} / \mathrm{kg})$ & 1700 & 600 & 100 \\
\hline & Organic nitrogen $(\mathrm{ON})(\mathrm{N} \%)$ & 0.17 & 0.06 & 0.01 \\
\hline & Organic carbon $(\mathrm{OC})(\mathrm{C} \%)$ & 1.04 & 0.32 & 0.36 \\
\hline & Organic matter (OM) (\%) & 6.72 & 2.68 & 3.35 \\
\hline & Mean grain size $(\mathrm{Mz})(\mu \mathrm{m})$ & 5.58 & 22.86 & 50.10 \\
\hline \multirow[t]{7}{*}{ May } & Moisture content (MC) $(\%)$ & 44.2 & 32.1 & 23.7 \\
\hline & Total phosphorus (TP) (mg/kg) & 611.4 & 383.2 & 440.3 \\
\hline & Total nitrogen (TN) (mg/kg) & 1800 & 700 & 700 \\
\hline & Organic nitrogen $(\mathrm{ON})(\mathrm{N} \%)$ & 0.18 & 0.07 & 0.07 \\
\hline & Organic carbon $(\mathrm{OC})(\mathrm{C} \%)$ & 1.35 & 0.28 & 0.29 \\
\hline & Organic matter $(\mathrm{OM})(\%)$ & 6.71 & 2.96 & 3.58 \\
\hline & Mean grain size $(\mathrm{Mz})(\mu \mathrm{m})$ & & & \\
\hline \multirow[t]{7}{*}{ August } & Moisture content (MC) $(\%)$ & 47.2 & 30.8 & 24.7 \\
\hline & Total phosphorus (TP) (mg/kg) & 609.5 & 402.1 & 545.1 \\
\hline & Total nitrogen (TN) (mg/kg) & 1500 & 700 & 800 \\
\hline & Organic nitrogen $(\mathrm{ON})(\mathrm{N} \%)$ & 0.15 & 0.07 & 0.08 \\
\hline & Organic carbon $(\mathrm{OC})(\mathrm{C} \%)$ & 1.05 & 0.33 & 0.29 \\
\hline & Organic matter $(\mathrm{OM})(\%)$ & 4.93 & 1.78 & 1.88 \\
\hline & Mean grain size $(\mathrm{Mz})(\mu \mathrm{m})$ & 7.14 & 19.79 & 49.28 \\
\hline \multirow[t]{7}{*}{ November } & Moisture content (MC) $(\%)$ & 45.5 & 35.7 & 21.9 \\
\hline & Total phosphorus (TP) (mg/kg) & 522.6 & 323.4 & 381.6 \\
\hline & Total nitrogen (TN) (mg/kg) & 1800 & 1200 & 400 \\
\hline & Organic nitrogen $(\mathrm{ON})(\mathrm{N} \%)$ & 0.18 & 0.12 & 0.04 \\
\hline & Organic carbon $(\mathrm{OC})(\mathrm{C} \%)$ & 1.03 & 0.54 & 0.31 \\
\hline & Organic matter $(\mathrm{OM})(\%)$ & 5.07 & 2.23 & 1.76 \\
\hline & Mean grain size $(\mathrm{Mz})(\mu \mathrm{m})$ & & & \\
\hline
\end{tabular}

\subsection{Clone library analysis}

Restriction profiles were digitally photographed and visually recognized using ChemiDocTM XRS imaging system (BioRad). All profiles were further sorted into patterns differentiated by the number and size of fragments using Quantity-One software (Bio-Rad). Clones with the same RFLP pattern were grouped into the same phylotype. Full-length $16 \mathrm{~S}$ rRNA region of at least one phylotype-representing clone was then sequenced. The number of redundant copies was also included in all the statistical calculations to avoid the potential biases in the microbial community parameters due to this pre-screening of representatives of each RFLP pattern. Poor-quality sequences and suspected chimeras were screened out using the Chimera check program (Maidak et al. 2001). Sequences were further assigned to operational taxonomic units (OTUs) at a cutoff value of $97 \%$ using DOTUR (Schloss and Handelsman
2005). For each non-chimera sequence, the GenBank BLAST program was used to determine the nearest phylogenetic neighbor sequence (Altschul et al. 1997).

\subsection{Statistical analysis}

The coverage of each $16 \mathrm{~S}$ rDNA clone library was calculated as $C=\left[1-\left(n_{1} / N\right)\right] \times 100$, where $n_{1}$ is the number of unique OTUs, and $N$ is the total number of clones in a library. This value approximated the probability that all the unique OTUs in a given sample were represented at least once in the library (Dang et al. 2008c). Estimations of the 16S rDNA phyogenetic diversity (Shannon-Wiener $H^{\prime}$ and Simpson $D$ ) and Pielou's evenness $(J)$ indices were calculated with the OTUs of each library. The equations were as follows: $H^{\prime}=$ $-\sum P_{i} \ln P_{i}$, where $P_{i}=n_{i} / N, n_{i}$ is the number of clones in the $i$ th OTU, and $N$ is the total number of clones in the sample; $D=1$ 
$-\sum P_{i}^{2} ; J=H^{\prime} / \mathrm{H}_{\max }$, where $H_{\max }$ is the theoretical maximum value for $H^{\prime}$ if all taxa in the sample were equally abundant. Rarefaction analysis and two nonparametric richness estimators, the abundance-based coverage estimator $\left(S_{\mathrm{ACE}}\right)$ and the bias-corrected $\mathrm{Chao}_{1}\left(S_{\mathrm{Chao} 1}\right)$, were calculated using the DOTUR software (Schloss and Handelsman 2005). These diversity indices and richness estimators are useful statistical tools to compare the relative complexity of communities and to assess the degree to which sampling effort is saturated.

The bacterial community classification was determined using the Unique Fraction (UniFrac) environmental clustering method (Lozupone et al. 2007), which takes the molecular evolutionary distances of the sequences for community similarity analysis. This multivariate statistical analysis of clone libraries is based on the different bacterial distributions of each sample and can show the differences of bacterial community structure among different sites and seasons. Canonical correspondence analysis (CCA) was performed to determine the environmental parameters best linked to community separation. A matrix of OTU abundance ratios for each sample was used as the basis of the community analysis. A matrix of environmental values (environmental factors $\times$ quadrats) was also established, which were applied into analyzing the relationships between the bacterial community structure and environmental conditions using CCA. These calculations were carried out with the CANOCO 4.5 software (Microcomputer Power, USA) (ter Braak and Smilauer 2002).

\section{Results}

\subsection{Physicochemical characteristics of sediment samples}

The physicochemical characteristics of sediment samples from the stations in four seasons were presented in Table 1. The sampling sites in JZB differed in trophic status. The highest average values for all parameters throughout the four seasons were found at station A5, which is located near the Licun River. The B2 station had the second highest average values for all parameters, and the lowest values were recorded in D7 station. Physicochemical characteristics in all stations also showed seasonal variations. For instance, concentrations of TP and OM were high in May and August, while concentrations of TN and $\mathrm{OC}$ were relatively higher, except for station D7, in November.

\subsection{RFLP and clone library analysis of the bacterial} community

For each of the 16 sediment samples collected from the four typical stations in four seasons, full-length 16S rRNA gene clone libraries were built and analyzed by the RFLP method.
A random of 180 clones in each library was selected for the RFLP analysis, and finally, 2560 positive and proper clones were screened from the total 2880 clones. Restriction enzyme digestion using MspI and HhaI showed 1231 different RFLP patterns occurred in the total 5120 RFLP patterns. Most of the RFLP patterns were comprised by only one or two clones, suggesting a high degree of interspecific genetic diversity (Michaud et al. 2004). In each RFLP pattern, both the phylotype-representing clone and the redundant copies were included in the calculations of the microbial community parameters. After sequencing, 1088 clones were valid for further genetic analysis. Based on a cutoff of $97 \%$ similarity level, in total, 746 unique operational taxonomic units (OTUs) were assigned. When all libraries were assembled separately, the numbers of OTUs ranged from 76 (station D7 in February) to 155 (station D1 in August), with an average of 123 (Table 2). Among all the 746 OTUs, 412 OTUs occurred in only one library, while the others existed in at least two libraries, indicating a heterogeneous distribution of most of the bacteria in the spatiotemporal profile of the Jiaozhou Bay.

The coverage of the recovered 16S rRNA phylotypes in clone libraries ranged widely from 22.4 to $47.6 \%$ and was not correlated with library size (Table 2). The highest and the lowest coverage were in Aug-A5 and Aug-D7, respectively, which was obtained near the mouth of Licun River and the open sea area, respectively. The rarefaction curves in Fig. 2 revealed high levels of bacterial complexity for marine sediment samples, as none has reached the curvilinear or plateau phase. The low coverage on average was consistent with the rarefaction results, indicating that the actual microbial community was far more diverse and all samples had potentially much more undetected OTUs. To compare the diversities and richness of the bacterial communities, the diversity indices and richness estimators were also calculated (Table 2). Since the Shannon index is always underestimated in the case of incomplete sampling (Hill et al. 2003), it is not an appropriate choice for this dataset because of the incomplete sampling as mentioned. However, each library's Shannon index in this study exhibited similar trend with the reciprocal Simpson index, and the most complex diversity was observed in AugD7 and the least in Aug-A5. The average reciprocal Simpson indexes results revealed a more even distribution of the phylotypes for the bacteria communities in B2 (74.12) and D7 (62.74) stations than in contaminated stations A5 (58.40) and D1 (56.91), which suggested that the diversity and evenness of bacterial community may have been negatively affected by sediment contaminations. Among the four seasons, the highest average Shannon index for all the sites was in November (4.58), followed by May (4.28), August (4.25), and the lowest February (4.19), showing a variation that possibly be associated with sea water temperature. The Simpson index values in the four seasons are highly consistent with the Shannon index analysis (Table 2). 
Table 2 Analyses of the 16 bacterial clone libraries in the Jiaozhou Bay

\begin{tabular}{|c|c|c|c|c|c|c|c|c|}
\hline Sample & $\begin{array}{l}\text { Shannon-Wiener } \\
\left(H^{\prime}\right)\end{array}$ & $\begin{array}{l}\text { Evenness } \\
(\mathrm{J})\end{array}$ & $\begin{array}{l}\text { Simpson's diversity } \\
\text { (1/dominance) }\end{array}$ & $\begin{array}{l}\text { No. of OTUs } \\
97 \%\end{array}$ & $\begin{array}{l}\text { Single OTU } \\
(\mathrm{nl})\end{array}$ & $\begin{array}{l}\text { Coverage } \\
(\%)\end{array}$ & $S_{\mathrm{ACE}}$ & $S_{\text {Chaol }}$ \\
\hline Feb-A5 & 4.255 & 0.971 & 58.320 & 108 & 61 & 0.435 & 248.80 & 194.37 \\
\hline Feb-B2 & 4.268 & 0.966 & 57.075 & 110 & 69 & 0.373 & 388.25 & 343.66 \\
\hline Feb-D1 & 4.196 & 0.984 & 60.714 & 85 & 60 & 0.294 & 271.90 & 267.66 \\
\hline Feb-D7 & 4.068 & 0.986 & 54.491 & 76 & 49 & 0.355 & 174.51 & 152.46 \\
\hline May-A5 & 4.558 & 0.977 & 80.772 & 133 & 88 & 0.338 & 452.35 & 379.42 \\
\hline May-B2 & 4.347 & 0.968 & 63.259 & 125 & 66 & 0.472 & 256.25 & 215.17 \\
\hline May-D1 & 4.120 & 0.963 & 47.751 & 95 & 60 & 0.368 & 367.59 & 293.25 \\
\hline May-D7 & 4.112 & 0.968 & 47.604 & 87 & 61 & 0.299 & 490.19 & 331.42 \\
\hline Aug-A5 & 3.736 & 0.828 & 10.689 & 149 & 78 & 0.477 & 397.66 & 391.30 \\
\hline Aug-B2 & 4.606 & 0.974 & 83.765 & 145 & 94 & 0.352 & 489.91 & 449.23 \\
\hline Aug-D1 & 3.843 & 0.846 & 14.587 & 155 & 84 & 0.458 & 675.00 & 675.00 \\
\hline Aug-D7 & 4.791 & 0.991 & 112.978 & 143 & 111 & 0.224 & 589.69 & 562.07 \\
\hline Nov-A5 & 4.566 & 0.979 & 83.834 & 133 & 88 & 0.338 & 415.22 & 405.46 \\
\hline Nov-B2 & 4.669 & 0.980 & 92.495 & 142 & 101 & 0.289 & 593.46 & 537.83 \\
\hline Nov-D1 & 4.749 & 0.987 & 104.602 & 145 & 104 & 0.283 & 404.89 & 404.89 \\
\hline Nov-D7 & 4.337 & 0.932 & 35.875 & 144 & 90 & 0.375 & 492.84 & 505.50 \\
\hline
\end{tabular}

OTU operational taxonomic units

\subsection{Taxonomic identification and phylogenetic analysis}

Diverse 16S rRNA gene sequences were recovered from the clone libraries. Although more than half (55\%) of the OTUs had quite high identities ( $\geq 97 \%$ identity) with known GenBank sequences, most of the nearest neighboring GenBank sequences were originally recovered from uncultured environmental bacteria. About $16.5 \%$ OTUs had quite low identities ( $<94 \%$ ) with known GenBank sequences, and the remaining OTUs ( $28.5 \%$ ) had moderate ( $\geq 94$ and $<97 \%$ ) identities with known GeneBank sequences. Due to low identity with known bacterial sequences of our 16S rRNA gene sequences, these sequences may represent the as-yetuncultivated novel bacteria in this typical semi-enclosed bay. The RDP classifier was also used to assign 16S rRNA gene sequences (Wang et al. 2007). The benthic bacterial communities in the JZB sediments displayed a highly diversified composition including members from seventeen bacterial phyla and some unclassified sequences $(0.85 \%)$. Proteobacteria (61.3\% of the total sequences), Acidobacteria (9.06 \%), Bacteroidetes (7.54\%), Planctomycetes (5.72\%), Actinobacteria (3.65\%), Verrucomicrobia (3.04\%), Chloroflexi (2.48 \%), and Nitrospirae (1.22\%) were the rather dominant groups in all samples. Members of Firmicutes, Fusobacteria, Cyanobacteria, Gemmatimonadete, Spirochaetes, Elusimicrobia, Deferribacteres, Lentisphaerae, and Deinococcus-Thermus were also found as minor phyla (ranging from 0.05 to $1 \%$ ) in the JZB sediments. Five subdivisions of the Proteobacteria presented in our libraries, including the $\gamma$ - $(32.8 \%), \delta$ - (22.68\%), $\alpha$ - (4.15\%), $\varepsilon$ $(0.91 \%)$ and $\beta$-Proteobacteria $(0.76 \%)$ (Fig. 3).

3.4 Spatiotemporal distribution of the sedimentary bacterial assemblages

The abundance and distribution of all bacterial assemblages in the 16 libraries, as well as their spatial and temporal variations, are illustrated in Fig. 3. Microbial community experienced more obvious changes in D1 and D7 sites than in $\mathrm{B} 2$ and $\mathrm{A} 5$ sites. Site D1 exhibited the most diverse microbial communities. The 16S rRNA gene sequences affiliated within the Proteobacteria were the most diverse and abundant in all JZB sediment bacteria clone libraries, showing a consistence with typical marine sediment environment. In total, 173, 135, and 38 OTUs were affiliated within the $\gamma-, \delta$-, and $\alpha$-Proteobacteria subdivision, respectively, representing the three most abundant subdivisions. Although these dominant bacterial communities were present in all the stations studied and throughout the year, in comparison, $\gamma$ - and $\delta$-Proteobacteria were slightly less abundant at the outer bay stations. For example, $\gamma$-Proteobacteria was less distributed in $\mathrm{D} 7$ station, and $\delta$-Proteobacteria was less in D1 station, especially in the Aug-D1 sample. $\alpha$ Proteobacteria were rarely observed in A5 stations. On the contrary, the Acidobacteria occurred more frequently in the D1 and D7 samples, especially in Nov-D1 sample. The Planctomycetes bacteria were also more prevailing in D1 samples. Finally, among the abundant genera, the Bacteroidetes were distributed relatively less in A5 and D1 station. 

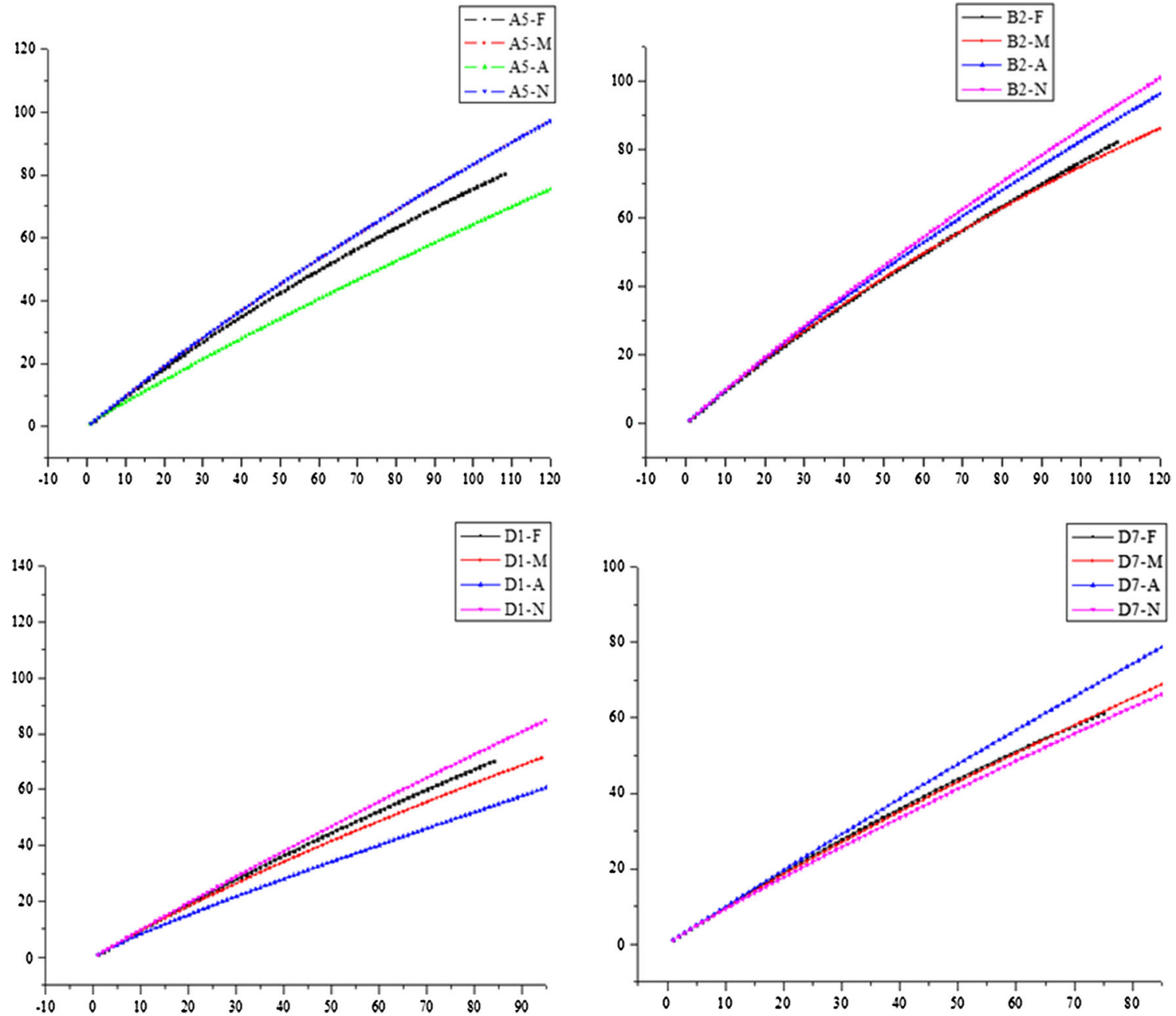

Fig. 2 Rarefaction curves of bacterial 16S rRNA gene clone libraries in the Jiaozhou Bay sediment (samples from four stations in four seasons). The phylotypes were determined with a $97 \%$ similarity cutoff value over 1088 nucleotides

No significant seasonal variation in bacterial community composition could be observed in the four sampling locations. The samples collected in February tended to be the most different (the least in abundance and diversity) from those collected in other months (Fig. 3). The four predominant phyla, Proteobacteria, Bacteroidetes, Acidobacteria, and Planctomycetes, were widely distributed in all months, and some seasonal differences were still observed. The $\gamma$-Proteobacteria occurred much more in August than in the other three seasons. The OTU percentage of the $\gamma$-Proteobacteria was $55 \%$ in the total OTUs of the Aug-D1 samples and was $52 \%$ in the AugA5 samples. The $\delta$-Proteobacteria as the second largest community member presented more in May samples. The bacteria related to $\alpha$-Proteobacteria could hardly be found in February samples. The Acidobacteria were more abundant in November. The Planctomycetes bacteria were obviously more abundant in August, and the Bacteroidetes were distributed relatively evenly over the temporal scale.
In addition to those predominant bacteria groups, some relatively minor bacterial groups were also observed to shift in response to spatial and temporal variations, indicating different environmental adaptation strategies of various bacteria. For instance, Chloroflexi was found in all the stations, but were less in B2 samples. Gemmatimonadetes was found in all libraries except the A5 and February samples. Fusobacteria lost its occurrence in May. Elusimicrobia occurred only in August and only in the two inner bay stations A5 and B2. Members of Cyanobacteria occurred only in B2 and D7 clone libraries in November. Lentisphaerae occurred only in May and in station D7. Deinococcus-Thermus occurred only in August in station D1.

\subsection{Community classification of bacterial assemblages}

The community assemblages were further compared using the obtained 16S rRNA gene sequences by the online program UniFrac. As shown in Fig. 4, the 16 samples clustered separately according mainly to the different stations, thereby 


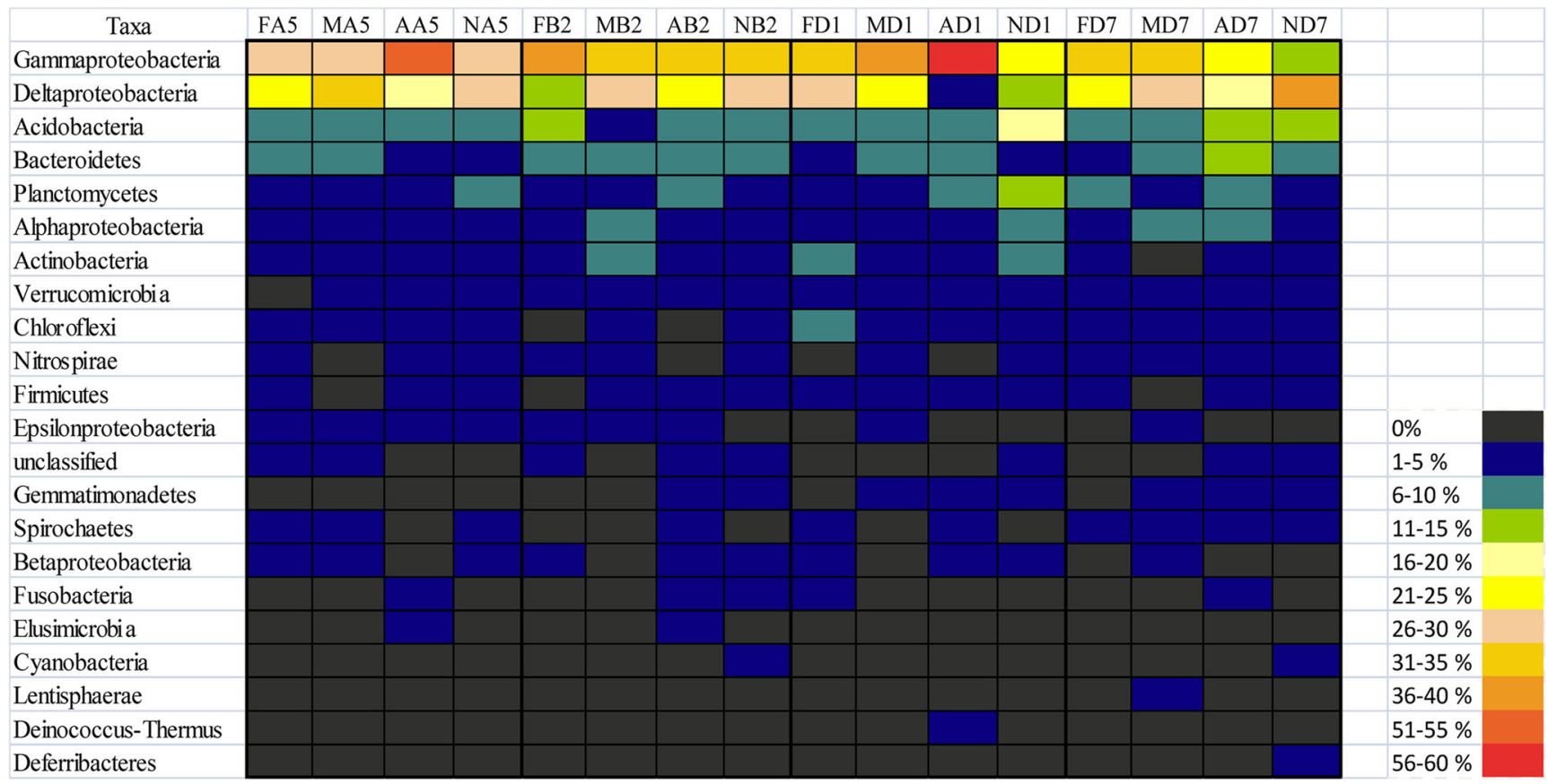

Fig. 3 Representation of different bacteria distribution and abundance at phylum levels with regard to sampling months and stations. Different colors correspond to the number of samples where the clones have been identified

illustrating a relatively more obvious spatial difference (Fig. 4). Bacterial assemblages of the D1 station appeared to represent the most distinct cluster, and the D1 samples in different seasons were separated in three main clusters. The D7 samples represented the second distinct cluster, in which all its libraries in four seasons were strictly classified into one distinct group. In the remaining stations, nearly all samples from the A5 and B2 station, except for the Feb-A5 and Feb-B2 samples, grouped together and finally formed one main cluster. Unlike the spatial distribution, seasonal variations were less pronounced in the bacterial communities and only slightly affected clustering. The May and August samples seemed to cluster more closely and that the bacterial community structure in February was pretty much different from the other three months. This is in agreement with general observations of seasonality of annual marine microbial communities.

Fig. 4 Dendrogram of the hierarchichial clustering analysis of the Jiaozhou Bay bacterial assemblages, constructed using the UniFrac normalized and weighted jackknife environment clusters statistical method

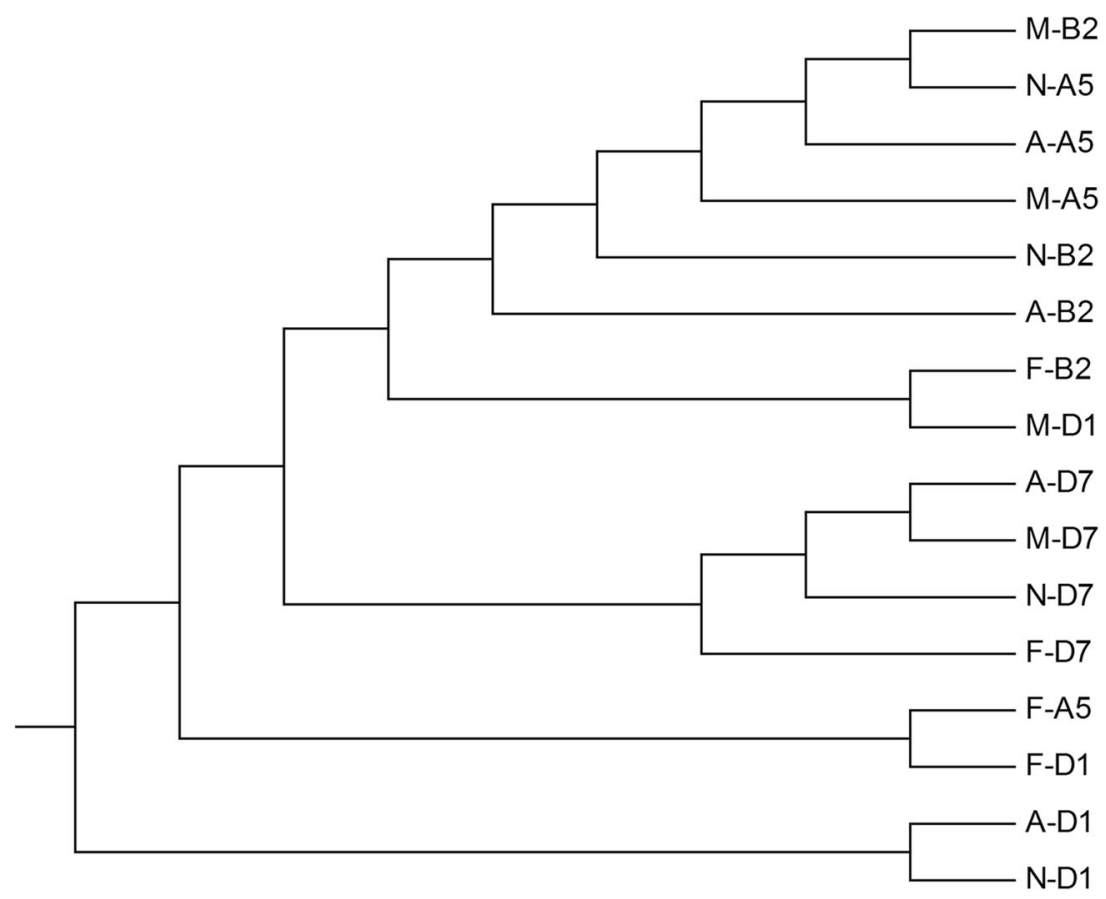


We used CCA to evaluate the effect of environmental variables on the bacterial compositions (Fig. 5). Results of CCA illustrated that the differences in bacterial community between the four sampling stations are not related to any of the environmental factors. None environmental parameters contributed significantly $(P<0.05)$ to variance in bacterial community. The eigenvalues of the first and second axis were 0.518 and 0.474 , respectively, and the first two ordination axes explained only $15.8 \%$ of the total variance in the bacteria composition.

\section{Discussion}

4.1 Bacterial taxonomic diversity in Jiaozhou Bay sediments

As a mixing environment between terrestrial and marine habitats, the coastal area is thought to have a significantly higher diversity of bacterial community than marine sediment (Allen et al. 2009; Zinger et al. 2011). Our results identified 17 bacterial phyla in the sediments of Jiaozhou Bay. To our knowledge, this is among the most diverse coastal sediment habitats in clone library studies so far (Zhang et al. 2008; Feng et al. 2009). The bacterial diversity in this study is also higher than that of our previous DGGE study, in which the bacterial composition in the sediments collected from ten different Jiaozhou Bay stations in four seasons were evaluated. In comparison, several bacterial groups were only found in the current study, such as the Planctomycetes, Verrucomicrobia,

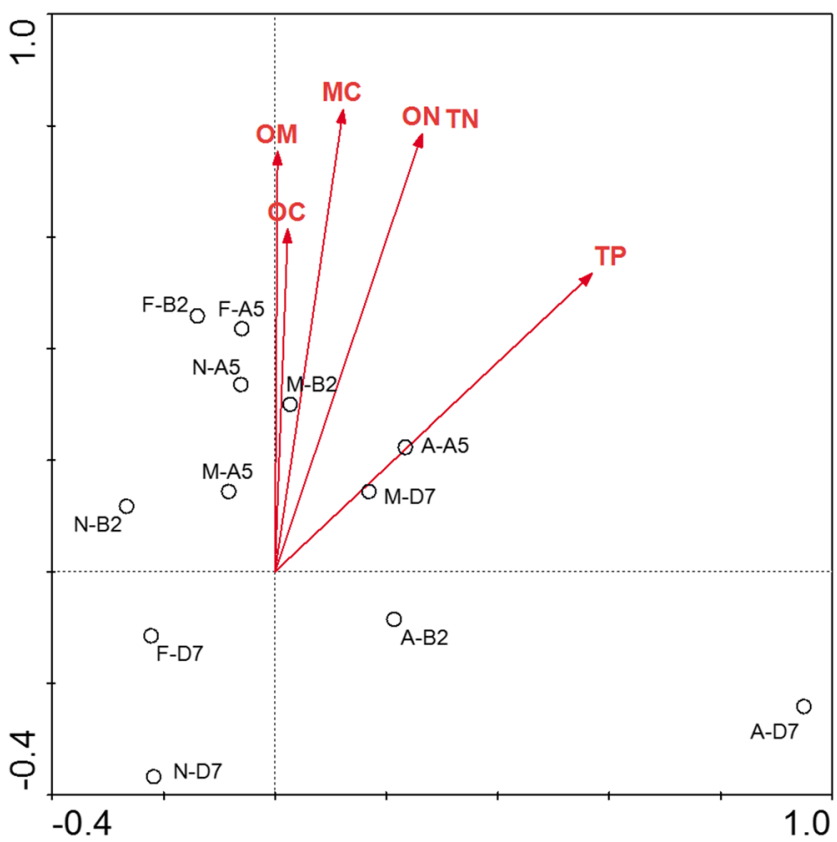

Fig. 5 Multivariate statistical analysis of correlations between environmental variables and distribution of bacteria community by CCA
Deferribacteres, Lentisphaerae, Deinococcus-Thermus, and Elusimicrobia, while the Bacillariophyta and Tenericutes previously detected by DGGE (Liu et al. 2011) were not found here. For the limited sensitivity of detection of rare community members by DGGE (Vallaeys et al. 1997), the absence in DGGE results may be attributed to the variation of species abundance. Moreover, the bacterial species in our current study were more diverse than those in other previous studies, which worked on the same Jiaozhou Bay sampling stations and also via clone library method (Doctoral thesis, unpublished data). Compared to other relevant reports, here we found for the first time the occurrence of Spirochaetes, Nitrospirae, Elusimicrobia, Deferribacteres, and Lentisphaerae bacteria groups in Jiaozhou Bay sediments (Jing et al. 2006; Bai et al. 2009). This difference in diversity may not only be due to PCR primer coverage and specificity but also may result from some experimental details that might improve the quality of our experiment (Dang et al. 2008c; Li et al. 2010). Indeed, some of the sediment bacterial groups uniquely found in the current study were also detected in previous surface-colonizing bacterial community analyses in Qingdao coastal seawater (Dang et al. 2008a, 2011). In the present study, the Power Soil DNA Extraction Kit was used, which has been demonstrated to be an efficient DNA extraction method for marine sediments. Three tubes of PCR products were pooled to reduce the biases of each individual reaction. The clones of each library were also selected from a single indicator plate to reduce the opportunity of sampling artificially redundant clones (Dang et al. 2009a). Thus, it further proved that the diversity of sediment bacteria in Jiaozhou Bay may have been underestimated in previous studies. For most of the time, it cannot be guaranteed that different methods will produce consistent results, as every approach has its technical advantages and disadvantages (Zeng et al. 2009; Ying et al. 2013). The size of clone library may be an important limit for its resolution (Sogin et al. 2006). Advances in sequencing technology are expanding our view of the microbial communities in unprecedented ways. New highthroughput pyrosequencing methods are increasing dramatically the number of sequences, allowing deeper coverage and improving our statistical power as well (Wang et al. 2012; Hu et al. 2013). A combination of more advanced methods may provide a comprehensive and complementary view in understanding of the marine sediment bacteria community.

Among the three predominant bacterial groups in our study, most of the Jiaozhou Bay sediment bacterial sequences had their closest matches originally detected in marine surface sediments and estuarine (Table S1, Electronic Supplementary Material), especially from the Yellow Sea, the Suez and Tokyo Bay, and the heavy metal contaminated marine sediments, indicating a significant similarity of the bacterial communities in these sediment environments. Our results here not only reflected a specific relationship between Jiaozhou Bay and 
the Yellow Sea but also supported the hypothesis of environmental control on the composition and distribution of microbial communities, especially the key bacteria groups. In comparable environments, similar bacterial communities might exist (Dang et al. 2009b).

\subsection{Factors shaping the bacterial community structure}

The UniFrac method combined the advantages of the molecular evolutionary information and the traditional ecological studies (Lozupone et al. 2007). In the present study, both the UniFrac environmental clustering (Fig. 4) and the composition of bacterial community (Fig. 3) revealed considerable heterogeneity of the sediment bacterial community in the four stations. By UniFrac analysis, the bacterial assemblages were divided into four main clusters corresponding to the four stations (Fig. 4). However, in our previous study including ten different Jiaozhou Bay stations in four seasons, the seasonal variation had stronger influence on the bacterial community composition than did the spatial variation in that the bacterial communities clustered according to seasons (Liu et al. 2011). Such season-driven shift in microbial composition was consistent with another bacterial spatiotemporal investigation, in which sediment samples from eight Jiaozhou Bay stations over four seasons were collected (Doctoral thesis, unpublished data). Therefore, it may possibly concluded that, if the whole Jiaozhou Bay areas are under consideration, season might be the driving force in variation of the sediment bacterial community structure under this large scale. While, as far as the four stations in this study are considered, it might be their geographic heterogeneity, containing strong physicochemical and biological gradients, that mainly shapes the benthic microbiomes. On the other hand, the UniFrac clustered mainly by stations, rather than seasons, reflected the distinction of the four sampling sites we chose in this study, and these four stations may symbolize four typical heterotypical environments in the Jiaozhou Bay.

Both our current and previous studies (Liu et al. 2011) showed that the bacterial community in sediments of A5 and B2 firstly grouped into one cluster, reflecting a similar bacterial community structure in these two stations. Similarly, Ren et al. (2006) divided the water bacterial community in Jiaozhou Bay into three distinct classes according to the three geographical types of the sampling locations: the innermost (i.e., station A5 and B2), the outside (i.e., station D7), and the transitional in the middle (i.e., station D1) of the Jiaozhou Bay. On the contrary, Dang et al. (2009b) found that the A5 station could be clearly distinguished from the B2 station based on total sedimentological, geochemical and physicochemical parameters, and the $\mathrm{A} 5$ and $\mathrm{B} 2$ stations might represent the worst and the best environmental conditions in Jiaozhou Bay, respectively. Their results further suggested that the nirSencoding bacterial assemblages of the A5 and D1 stations grouped together, showing clearly difference from that of the B2 station. Such differences between our results and theirs might due to the total bacterial community and the functional denitrifying community that the two studies had differently focused on. Hybrid environmental conditions possibly have more complicated influences on the hybrid total bacterial communities than on certain functional bacterial communities. However, Fig. 4 shows that the A5 and D1 samples clustered together in February, which was consistent with the results by Dang et al. (2009b). One explanation may be that both the sea water and the sediment are the cleanest in February in Jiaozhou Bay. Low sea temperature and less active biologic metabolism resulted in a more important influence by pollutions. Thus, the polluted situations caused a similar effect on these two stations, which receive most of the inflow contaminations in the Jiaozhou Bay.

Interestingly, nearly all studies on the microbial communities in Jiaozhou Bay sediment indicated that the bacterial assemblage in the D1 station was the most distinct from other stations (Dang et al. 2009b, 2010a). Our current study here proved one more time the most special features of bacterial structure in the D1 station. An anticlockwise eddy was found in the north of Huangdao at station D1 (Liu et al. 2004), which might make the in situ hydrological conditions more stagnant than those of the other stations in Jiaozhou Bay (Dang et al. 2009b). This may reduce material transport and water exchange between D1 station and the Yellow Sea outside. Station D1 is also the heaviest contaminated station by oil from the nearby crude oil refining plants (Dang et al. 2010a). It was reported that there had been about 208 sporadic oil-spilling events with 5810-t oil leakage from 1974 since the first use of Huangdao oil port started (Jing et al. 2006). Therefore, the unique sediment bacterial assemblage in station D1 (Figs. 3 and 4) might be a result of the most unique in situ hydrological, geochemical, or pollution condition.

There are a variety of environmental conditions that might influence the sedimentological condition and thus the sedimentary bacterial assemblages, including the in situ hydrological regime, such as currents (Hamdan et al. 2013), tides (Gobet et al. 2012), upwelling (Kuypers et al. 2005), lateral transport (Dalsgaard et al. 2005), water mixing and exchange, and the intensity and dynamics of these activities (Dang et al. 2008d, 2013). Certain geochemical background, such as sediment $\mathrm{NH}_{3}$, OrgC (Jorgensen et al. 2012) and OrgN (Martiny et al. 2011), mineral (Jorgensen et al. 2012), salinity (Bolhuis and Stal 2011), and pH (Lozupone and Knight 2007); and many sedimentological factors, such as median grain size (Jackson and Weeks 2008) and the electrical conductivity, had also been identified as potentially the key regulators of the bacterial composition, community structure, abundance, and distribution in the marine sediment. Dang et al. (2010a) found that the sedimentological factors dominated the geochemical and physicochemical factors for the distinction of 
sediment anammox bacterial community between station B2 and D1 in Jiaozhou Bay, and have significant impacts on the spatial distribution between B2 and the other stations. In this study, none of the present environmental parameters contributed significantly $(P<0.05)$ to variance in bacterial community. The differences in bacterial community are not related to any of those measured environmental factors. The low coverage of clone libraries might be one reason for the complicated CCA results we had got. Rarefaction curves showed that the diversity of our sediment samples was quite high (Fig. 2). Therefore, the diversity suggested by the data was not necessarily representative of the in situ bacteria communities in the sediments (von Wintzingerode et al. 1997). It may be biased to compute statistical correlations between the environmental variables and the bacteria community structure based on libraries with low coverage. Besides, the lack of the environmental parameters of D1 station probably also contributed to the difficulty in pointing out the most influential environmental factor clearly. To gain definite conclusions, more samples, more extensive sequences, and also more complete environmental parameters should be analyzed in future studies.

\subsection{Bacterial communities in comparable habits}

Microbial environment-specificity indicates that the bacterial community may provide a bioindicator of the shift of the sedimentary physicochemical and geochemical characteristics (Dang et al. 2009a, 2010b). Proteobacteria, Acidobacteria, and Bacteroidetes were present in all stations and all seasons in our study. These phyla have been always identified as dominant groups in sediment environments and were generally important contributors to biogeochemical processes (Durbin and Teske 2011; Wang et al. 2012). Proteobacteria were dominant in most surface marine sediments, comprising $>50 \%$ of the microbial biomass (Bowman and McCuaig 2003), and it seems that $\gamma$-Proteobacteria was the most significant clade in marine sediments (Feng et al. 2009; Wang et al. 2012). Global distribution might be an important ecological characteristic of these marine bacteria groups, and many corresponding clusters included might have flexible adaptation to the various marine sediment environments. Most members of $\delta$-Proteobacteria are chemoorganotrophs related to the sulfate-reducing bacteria (SRB), which play an important role for sulphur cycling in global marine sediments (Ravenschlag et al. 2000). Besides SRB, potential sulfuroxidizing bacteria (SOB), which belong to $\varepsilon_{-}, \gamma-$, and $\alpha$ subdivision of Proteobacteria also constitute an important fraction in bacterial communities of marine sediments (Zeng et al. 2009). Similar SOB sequences have also been detected abundantly in the surfaces of submerged carbon steel coupons in Qingdao coastal seawater (Dang et al. 2011). In the eastern part of the Jiaozhou Bay, increasing nutrient input due to intensive agriculture and industry causes serious eutrophication, which may be related to the high levels of $\delta$ and $\varepsilon$-Proteobacteria in the A5 station. However, in another contaminated D1station, a possible explanation is needed for the conflicting result that $\delta$-Proteobacteria was found significantly less in Aug-D1 samples. It has been demonstrated that the $\beta$-Proteobacteria usually constitute a more common fraction in freshwater environment and negatively related to water salinity, as well as they are believed to share the ability to degrade complex organic macromolecules with the Bacteroidetes (Eiler and Bertilsson 2004; Feng et al. 2009). In our study, the $\beta$-Proteobacteria was the least abundant in station D7, which belongs to the outer bay area and meet the least freshwater input. Previous findings have highlighted the importance of Bacteroidetes, formerly known as the Cytophaga-Flavobacteria-Bacteroidetes phylum, on submerged surfaces, suspended particles, and during phytoplankton blooms (Eiler and Bertilsson 2004). Bacteroidetes has been shown especially abundant in samples derived from Cyanobacterial aggregates (Tang et al. 2009). In this study, the higher percentage of Bacteroidetes and the only observation of Cyanobacterial in B2 and D7 stations might be reasonable.

All the obvious spatial heterogeneity will make the microbe-environment relationship even clearer. If the suite of environmental factors responsible for structuring the Jiaozhou Bay sediment bacterial communities is known, then samples with similar values for these variables would be expected to contain rather similar bacteria communities.

\section{Conclusions}

Bacterial community composition in sediments of four typical stations in Jiaozhou Bay over four seasons were assessed by clone libraries. Full-length bacterial 16S rRNA gene sequences and the taxonomical analyses showed the existence of extremely diverse bacterial communities in this hypernutrified semi-enclosed bay. UniFrac analysis revealed that the community structures clustered with respect to different stations. Data from this study and our previous work were compared to address this geographic heterogeneity, which might shape the benthic microbiomes. Moreover, Jiaozhou Bay may be affected by multi-dimension anthropogenic activities. Our study provides new information and is a useful indicator for environmental assessment of Jiaozhou Bay and will help to enhance the overall understanding of the microbial ecology.

Acknowledgments This work was supported by the China National Science Foundation grant 40821004 . We are also indebted to the members of the Ecological Environment Monitoring Station in Jiaozhou Bay for providing measurements of the physicochemical parameters of the sediment. 


\section{References}

Aguiló-Ferretjans MM, Bosch R, Martín-Cardona C, Lalucat J, Nogales B (2008) Phylogenetic analysis of the composition of bacterial communities in human-exploited coastal environments from Mallorca Island (Spain). Syst Appl Microbiol 31(3):231-240

Allen MA, Goh F, Burns BP, Neilan BA (2009) Bacterial, archaeal and eukaryotic diversity of smooth and pustular microbial mat communities in the hypersaline lagoon of Shark Bay. Geobiology 7(1):8296

Altschul SF, Madden TL, Schäffer AA, Zhang J, Zhang Z, Miller W, Lipman DJ (1997) Gapped BLAST and PSI-BLAST: a new generation of protein database search programs. Nucleic Acids Res 25(17):3389-3402

Bai J, Li H, Zhao Y (2009) Bacterial distribution at different stations in the Northern Yellow Sea. Acta Microbiol Sin 3:343-350

Baker GC, Smith JJ, Cowan DA (2003) Review and re-analysis of domain-specific 16S primers. J Microbiol Methods 55(3):541-555

Bertics VJ, Ziebis W (2009) Biodiversity of benthic microbial communities in bioturbated coastal sediments is controlled by geochemical microniches. ISME J 3(11):1269-1285

Bissett A, Bowman J, Burke C (2006) Bacterial diversity in organicallyenriched fish farm sediments. FEMS Microbiol Ecol 55(1):48-56

Bolhuis H, Stal LJ (2011) Analysis of bacterial and archaeal diversity in coastal microbial mats using massive parallel 16S rRNA gene tag sequencing. ISME J 5(11):1701-1712

Bowman JP, McCuaig RD (2003) Biodiversity, community structural shifts, and biogeography of prokaryotes within antarctic continental shelf sediment. Appl Environ Microbiol 69(5):2463-2483

Dai J, Song J, Li X, Yuan H, Li N, Zheng G (2007) Environmental changes reflected by sedimentary geochemistry in recent hundred years of Jiaozhou Bay, North China. Environ Pollut 145(3):656-667

Dalsgaard T, Thamdrup B, Canfield DE (2005) Anaerobic ammonium oxidation (anammox) in the marine environment. Res Microbiol 156(4):457-464

Dang H, Li T, Chen M, Huang G (2008a) Cross-ocean distribution of Rhodobacterales bacteria as primary surface colonizers in temperate coastal marine waters. Appl Environ Microbiol 74:52-60

Dang H, Ren J, Song L, Sun S, An L (2008b) Diverse tetracycline resistant bacteria and resistance genes from coastal waters of Jiaozhou Bay. Microb Ecol 55(2):237-246

Dang H, Ren J, Song L, Sun S, An L (2008c) Dominant chloramphenicolresistant bacteria and resistance genes in coastal marine waters of Jiaozhou Bay, China. World J Microbiol Biotechnol 24(2):209-217

Dang H, Zhang X, Sun J, Li T, Zhang Z, Yang G (2008d) Diversity and spatial distribution of sediment cammonia-oxidizing crenarchaeota in response to estuarine and environmental gradients in the Changjiang Estuary and East China Sea. Microbiology 154:2084-2095

Dang H, Li J, Chen M, Li T, Zeng Z, Yin X (2009a) Fine-scale vertical distribution of bacteria in the East Pacific deep-sea sediments determined via $16 \mathrm{~S}$ rRNA gene T-RFLP and clone library analyses. World J Microbiol Biotechnol 25(2):179-188

Dang H, Wang C, Li J, Li T, Tian F, Jin W, Ding Y, Zhang Z (2009b) Diversity and distribution of sediment NirS-encoding bacterial assemblages in response to environmental gradients in the eutrophied Jiaozhou Bay, China. Microb Ecol 58(1):161-169

Dang H, Chen R, Wang L, Guo L, Chen P, Tang Z, Tian F, Li S, Klotz MG (2010a) Environmental factors shape sediment anammox bacterial communities in hypernutrified Jiaozhou Bay, China. Appl Environ Microbiol 76(21):7036-7047. doi:10.1128/aem.01264-10

Dang H, Li J, Chen R, Wang L, Guo L, Zhang Z, Klotz MG (2010b) Diversity, abundance, and spatial distribution of sediment ammoniaoxidizing betaproteobacteria in response to environmental gradients and coastal eutrophication in Jiaozhou Bay, China. Appl Environ Microbiol 76(14):4691-4702
Dang H, Chen R, Wang L, Shao S, Dai L, Ye Y, Guo L, Huang G, Klotz MG (2011) Molecular characterization of putative biocorroding microbiota with a novel niche detection of Epsilon- and Zetaproteobacteria in Pacific Ocean coastal seawaters. Environ Microbiol 13:3059-3074

Dang H, Zhou H, Zhang Z, Yu Z, Hua E, Liu X, Jiao N (2013) Molecular detection of Candidatus Scalindua pacifica and environmental responses of sediment anammox bacterial community in the Bohai Sea, China. PLoS ONE 8:e61330

Danovaro R, Pusceddu A (2007) Biodiversity and ecosystem functioning in coastal lagoons: does microbial diversity play any role? Estuar Coast Shelf Sci 75(1-2):4-12

Deng B, Zhang J, Zhang G, Zhou J (2010) Enhanced anthropogenic heavy metal dispersal from tidal disturbance in the Jiaozhou Bay, North China. Environ Monit Assess 161(1-4):349-358

Durbin AM, Teske A (2011) Microbial diversity and stratification of South Pacific abyssal marine sediments. Environ Microbiol 13(12):3219-3234

Eiler A, Bertilsson S (2004) Composition of freshwater bacterial communities associated with cyanobacterial blooms in four Swedish lakes. Environ Microbiol 6(12):1228-1243

Feng B-W, Li X-R, Wang J-H, Hu Z-Y, Meng H, Xiang L-Y, Quan Z-X (2009) Bacterial diversity of water and sediment in the Changjiang estuary and coastal area of the East China Sea. FEMS Microbiol Ecol 70(2):236-248

Gao X, Chen C-TA (2012) Heavy metal pollution status in surface sediments of the coastal Bohai Bay. Water Res 46(6):1901-1911

Gobet A, Boer SI, Huse SM, van Beusekom JEE, Quince C, Sogin ML, Boetius A, Ramette A (2012) Diversity and dynamics of rare and of resident bacterial populations in coastal sands. ISME J 6(3):542-553

Hamdan LJ, Coffin RB, Sikaroodi M, Greinert J, Treude T, Gillevet PM (2013) Ocean currents shape the microbiome of Arctic marine sediments. ISME J 7(4):685-696

Hill TCJ, Walsh KA, Harris JA, Moffett BF (2003) Using ecological diversity measures with bacterial communities. FEMS Microbiol Ecol 43(1):1-11

Hu H-W, Zhang L-M, Dai Y, Di H-J, He J-Z (2013) pH-dependent distribution of soil ammonia oxidizers across a large geographical scale as revealed by high-throughput pyrosequencing. J Soils Sediments 13(8):1439-1449

Jackson CR, Weeks AQ (2008) Influence of particle size on bacterial community structure in aquatic sediments as revealed by $16 \mathrm{~S}$ rRNA gene sequence analysis. Appl Environ Microbiol 74(16):5237-5240

Jing R, Hongyue D, Linsheng S, Song S, Liguo A (2006) Bacterial and cyanobacterial diversities determined by T-RFLP analyses in the Jiaozhou Bay. Acta Oceanol Sin 25(4):113-123

Jorgensen SL, Hannisdal B, Lanzén A, Baumberger T, Flesland K, Fonseca R, Øvreås L, Steen IH, Thorseth IH, Pedersen RB, Schleper C (2012) Correlating microbial community profiles with geochemical data in highly stratified sediments from the Arctic MidOcean Ridge. Proc Natl Acad Sci 109(42):E2846-E2855

Kuypers MMM, Lavik G, Woebken D, Schmid M, Fuchs BM, Amann R, Jørgensen BB, Jetten MSM (2005) Massive nitrogen loss from the Benguela upwelling system through anaerobic ammonium oxidation. Proc Natl Acad Sci U S A 102(18):6478-6483

Lachmund C, Köcher B, Manz W, Heininger P (2003) Chemical and microbiological in situ characterization of benthic communities in sediments with different contamination levels. J Soils Sediments 3(3):188-196

Li M, Hong Y, Klotz M, Gu J-D (2010) A comparison of primer sets for detecting 16S rRNA and hydrazine oxidoreductase genes of anaerobic ammonium-oxidizing bacteria in marine sediments. Appl Microbiol Biotechnol 86(2):781-790

Liu Z, Wei H, Liu G, Zhang J (2004) Simulation of water exchange in Jiaozhou Bay by average residence time approach. Estuar Coast Shelf Sci 61(1):25-35 
Liu SM, Zhang J, Chen HT, Zhang GS (2005) Factors influencing nutrient dynamics in the eutrophic Jiaozhou Bay, North China. Prog Oceanogr 66(1):66-85

Liu X, Xiao T, Luan Q, Zhang W, Wang M, Yue H (2011) Bacterial diversity, composition and temporal-spatial variation in the sediment of Jiaozhou Bay, China. Chin J Oceanol Limnol 29(3): 576-590

Lozupone CA, Knight R (2007) Global patterns in bacterial diversity. Proc Natl Acad Sci 104(27):11436-11440

Lozupone CA, Hamady M, Kelley ST, Knight R (2007) Quantitative and qualitative $\beta$ diversity measures lead to different insights into factors that structure microbial communities. Appl Environ Microbiol 73(5):1576-1585

Maidak BL, Cole JR, Lilburn TG, Parker CT Jr, Saxman PR, Farris RJ, Garrity GM, Olsen GJ, Schmidt TM, Tiedje JM (2001) The RDP-II (ribosomal database project). Nucleic Acids Res 29(1):173-174

Martiny JBH, Eisen JA, Penn K, Allison SD, Horner-Devine MC (2011) Drivers of bacterial $\beta$-diversity depend on spatial scale. Proc Natl Acad Sci 108(19):7850-7854

Michaud L, Di Cello F, Brilli M, Fani R, Lo Giudice A, Bruni V (2004) Biodiversity of cultivable psychrotrophic marine bacteria isolated from Terra Nova Bay (Ross Sea, Antarctica). FEMS Microbiol Lett 230(1):63-71

Ravenschlag K, Sahm K, Knoblauch C, Jørgensen BB, Amann R (2000) Community structure, cellular rRNA content, and activity of sulfatereducing bacteria in marine arctic sediments. Appl Environ Microbiol 66(8):3592-3602

Ren J, Dang H, Song L, Sun S, An L (2006) Bacterial and cyanobacterial diversities determined by T-RFLP analyses in the Jiaozhou Bay. Acta Oceanologica Sinica 25(4):113-123

Schloss PD, Handelsman J (2005) Introducing DOTUR, a computer program for defining operational taxonomic units and estimating species richness. Appl Environ Microbiol 71(3):1501-1506

Shi J, Li G, Wang P (2011) Anthropogenic influences on the tidal prism and water exchanges in Jiaozhou Bay, Qingdao, China. J Coast Res 27(1):57-72

Sogin ML, Morrison HG, Huber JA, Welch DM, Huse SM, Neal PR, Arrieta JM, Herndl GJ (2006) Microbial diversity in the deep sea and the underexplored "rare biosphere". Proc Natl Acad Sci 103(32):12115-12120
Sun MY, Dafforn KA, Brown MV, Johnston EL (2012) Bacterial communities are sensitive indicators of contaminant stress. Mar Pollut Bull 64(5):1029-1038

Tang X, Gao G, Qin B, Zhu L, Chao J, Wang J, Yang G (2009) Characterization of bacterial communities associated with organic aggregates in a large, shallow, eutrophic freshwater lake (Lake Taihu, China). Microb Ecol 58(2):307-322

ter Braak CJF, Smilauer P (2002) CANOCO reference manual and CanoDraw for Windows user's guide : software for canonical community ordination (version 4.5). Biometris, Wageningen

Vallaeys T, Topp E, Muyzer G, Macheret V, Laguerre G, Rigaud A, Soulas G (1997) Evaluation of denaturing gradient gel electrophoresis in the detection of $16 \mathrm{~S}$ rDNA sequence variation in rhizobia and methanotrophs. FEMS Microbiol Ecol 24(3):279-285

von Wintzingerode F, Göbel UB, Stackebrandt E (1997) Determination of microbial diversity in environmental samples: pitfalls of PCR-based rRNA analysis. FEMS Microbiol Rev 21(3):213-229

Wang Q, Garrity GM, Tiedje JM, Cole JR (2007) Naïve Bayesian classifier for rapid assignment of rRNA sequences into the new bacterial taxonomy. Appl Environ Microbiol 73(16):5261-5267

Wang C, Dang H, Ding Y (2008) Incidence of diverse integrons and $\beta$ lactamase genes in environmental Enterobacteriaceae isolates from Jiaozhou Bay, China. World J Microbiol Biotechnol 24(12):2889-2896

Wang Y, Sheng H-F, He Y, Wu J-Y, Jiang Y-X, Tam NF-Y, Zhou H-W (2012) Comparison of the levels of bacterial diversity in freshwater, intertidal wetland, and marine sediments by using millions of Illumina tags. Appl Environ Microbiol 78(23):8264-8271

Ying J-Y, Zhang L-M, Wei W-X, He J-Z (2013) Effects of land utilization patterns on soil microbial communities in an acid red soil based on DNA and PLFA analyses. J Soils Sediments 13(7):1223-1231

Zeng Y, Zheng T, Li H (2009) Community composition of the marine bacterioplankton in Kongsfjorden (Spitsbergen) as revealed by $16 \mathrm{~S}$ rRNA gene analysis. Polar Biol 32(10):1447-1460

Zhang W, Ki J-S, Qian P-Y (2008) Microbial diversity in polluted harbor sediments I: bacterial community assessment based on four clone libraries of 16S rDNA. Estuar Coast Shelf Sci 76(3):668-681

Zinger L, Amaral-Zettler LA, Fuhrman JA, Horner-Devine MC, Huse SM, Welch DBM, Martiny JBH, Sogin M, Boetius A, Ramette A (2011) Global patterns of bacterial beta-diversity in seafloor and seawater ecosystems. PLoS ONE 6(9):e24570 